\title{
Paracetamol and analgesic nephropathy: Are you kidneying me?
}

This article was published in the following Dove Press journal:

International Medical Case Reports Journal

15 December 2014

Number of times this article has been viewed

\section{Freya Waddington \\ Mark Naunton \\ Jackson Thomas}

Faculty of Health, University of Canberra, Canberra, ACT, Australia
Correspondence: Freya Waddington Faculty of Health, University of Canberra, University Drive, Bruce, Canberra,

ACT 2617, Australia

Tel +6I 2 620I 2462

Fax +6I 2 620I 5727

Email freya.waddington@canberra.edu.au
Introduction: Analgesic nephropathy is a disease resulting from the frequent use of combinations of analgesic medications over many years, leading to significant impairment of renal function. The observation of a large number of cases of renal failure in patients abusing analgesic mixtures containing phenacetin led to the initial recognition of the nephrotoxicity from the use of analgesics. Phenacetin was subsequently exclusively blamed for this disease. However, the role of a single analgesic as a sole cause of analgesic nephropathy was challenged, and a number of researchers have since attempted to determine the extent of involvement of other analgesics including nonsteroidal anti-inflammatory drugs (NSAIDs), aspirin, and paracetamol.

Case presentation: We present the case of an 83-year-old woman with a history of NSAIDinduced nephropathy with poor pain control and reluctance to use paracetamol. We attempt to briefly review the evidence of paracetamol being implicated in the development of analgesicinduced nephropathy.

Conclusion: There is a lack of concrete data regarding causative analgesics, including paracetamol. Patients should therefore not be withheld paracetamol, an effective and commonly recommended agent, for fear of worsening renal function.

Keywords: kidney, paracetamol, nephropathy, phenacetin

\section{Introduction}

We present a case of poor pain control and reluctance to use paracetamol in an elderly patient who had a history of nonsteroidal anti-inflammatory drug (NSAID)-induced nephropathy. We also attempt to briefly review the evidence of paracetamol being implicated in the development of analgesic-induced nephropathy.

\section{Case details}

Mrs MJ (83 years old) was referred for a routine Home Medicines Review in view of her multiple medications (Table 1). Home Medicines Review is a government-funded program in Australia that allows a pharmacist to review patients' medications at their homes and make recommendations to their general practitioners. ${ }^{1,2}$

Mrs MJ's medical history included: atrial fibrillation, analgesic nephropathy (AN), chronic kidney disease (stage 3, estimated glomerular filtration rate $60 \mathrm{~mL} / \mathrm{min} / 1.73 \mathrm{~m}^{2}$ ), gastroesophageal reflux disease, vitamin $\mathrm{B}_{12}$ deficiency, hypertension, hypercholesterolemia, hyperhomocysteinemia, hypothyroidism, myocardial infarction (two in the 1970s), degenerative spondylolisthesis, and transient ischemic attack.

At review, Mrs MJ described persistent back pain, but was reluctant to take paracetamol, due to her renal disease and previously documented analgesic-induced 
Table I Mrs MJ's medication profile

\begin{tabular}{ll}
\hline Medication & Dose and frequency \\
\hline Amlodipine $5 \mathrm{mg}$ & One tablet daily \\
Irbesartan $300 \mathrm{mg}$ & One tablet daily \\
Sotalol $80 \mathrm{mg}$ & Half a tablet twice daily \\
Moxonidine $200 \mu \mathrm{g}$ & One tablet daily \\
Simvastatin $40 \mathrm{mg}$ & One tablet at night \\
Dabigatran $150 \mathrm{mg}$ & One tablet twice a day \\
Calcium $600 \mathrm{mg}$ & One tablet daily \\
Thyroxine $50 \mu \mathrm{g}$ & One tablet daily \\
Pantoprazole $40 \mathrm{mg}$ & One tablet when required \\
Paracetamol SR $665 \mathrm{mg}$ & (usually once a week) \\
Paracetamol $500 \mathrm{mg} /$ codeine $30 \mathrm{mg}$ & Not using (prescribed one \\
Folic acid $0.5 \mathrm{mg}$ & tablet three times a day) \\
Vitamin $\mathrm{B}_{6} 240 \mathrm{mg}$ & One tablet at night \\
Vitamin $\mathrm{B}_{12} 100 \mu \mathrm{g}$ & One tablet daily \\
\hline
\end{tabular}

nephropathy in 1999. The patient had been told by health professionals to be careful with "some painkillers" to avoid further kidney damage, and subsequently had chosen to avoid paracetamol. The patient was unsure which health professional had told her to avoid paracetamol, but had decided it would be prudent to avoid "all painkillers", and she could not recall a health professional telling her paracetamol was safe. Further, it was documented that the patient had previously experienced acute renal failure from the use of an NSAID. The patient was unsure which NSAID had caused her acute kidney failure, and it was not documented in her medical history.

\section{Discussion}

\section{Analgesic nephropathy}

Chronic pain is a treatable condition that at any one point in time affects $20 \%-46 \%$ of community-dwelling older adults and $28 \%-73 \%$ of residents in aged-care facilities. ${ }^{3}$ A number of practice guidelines and literature reviews relating to the management of chronic pain in the elderly exist, with paracetamol being the first-line management option., ${ }^{3,4}$

A daily dose of both analgesic and anti-inflammatory medications is common practice among millions of patients experiencing chronic pain. ${ }^{5}$ Paracetamol is used alongside NSAIDs to assist in managing inflammatory conditions, such as gout or rheumatoid arthritis. ${ }^{6}$ NSAIDs are more effective than paracetamol for persistent inflammatory pain; however, they are associated with gastrointestinal side effects (eg, ulcers, bleeding), cardiovascular side effects (eg, hypertension, exacerbation of heart failure), and worsening of chronic renal failure. ${ }^{3,4}$ NSAIDs are best avoided in the elderly despite their efficacy, and if they are required to use them, they should be given in the lowest possible dose for the shortest period. ${ }^{3}$ The long-term effects of other analgesics (particularly paracetamol) on the kidneys have been debated at length. ${ }^{7,8}$

Currently, there are two recognized forms of AN: NSAIDassociated nephropathy and classic AN. NSAID-induced nephropathy is a widely reviewed condition. ${ }^{9}$ The nephrotoxicity of NSAIDs is mediated via nonspecific blocking of cyclooxygenase, subsequent inhibition of prostaglandin synthesis leading to vasoconstriction, and reversible renal impairment in volumecontracted states. ${ }^{9}$ This may lead to acute tubular necrosis and acute renal failure. NSAIDs also produce interstitial nephritis and papillary necrosis, resulting in chronic renal failure. ${ }^{9}$

The observation of large numbers of cases of renal failure in patients abusing analgesic mixtures containing phenacetin (termed phenacetin nephropathy) led to the initial recognition of nephrotoxicity from the use of analgesics. ${ }^{10}$ However, the role of a single analgesic as a sole cause of AN was challenged, leading to the redefinition of AN in 1996 as "a disease resulting from the frequent use of combinations of analgesic medications over many years, usually codeine or caffeine". ${ }^{10}$

Phenacetin was introduced as an analgesic in 1887 , soon followed by paracetamol in $1893 .{ }^{11}$ Phenacetin was popular due to its long duration of action; however, it had weaker antipyretic effects when compared to paracetamol. ${ }^{11}$ It took scientists nearly 50 years to discover that paracetamol is the major metabolite of phenacetin, thus accounting for phenacetin's analgesic effect (Figure 1). ${ }^{11}$

In the 1970 s, AN as a cause of end-stage renal disease reached its peak in Australia, with the condition being responsible for an estimated $20 \%$ of patients requiring renal replacement therapy. ${ }^{12}$ As a response to this, phenacetin was removed from Vincents ${ }^{\circledR}$ and Bex ${ }^{\circledR}$ (the most frequently used analgesic products) in 1967 and 1975, respectively. ${ }^{13}$ In 1977 , phenacetin was legally banned from all medical preparations in Australia, and all over-the-counter combination analgesic products were banned in 1979. ${ }^{13}$ Phenacetin was later removed from the Canadian market in 1978, and in 1983 from the US. ${ }^{14,15}$ Similarly, phenacetin was banned from the UK in 1980, and in Belgium phenacetin was removed from the two most frequently "abused" preparations in 1972 and 1981, followed by a total legal ban in $1988 .{ }^{15,16}$ Since this time, the exclusive role of phenacetin has been questioned in the development of nephropathy.

Researchers have proposed that paracetamol, not phenacetin, accumulated in the renal papilla, and in animal 


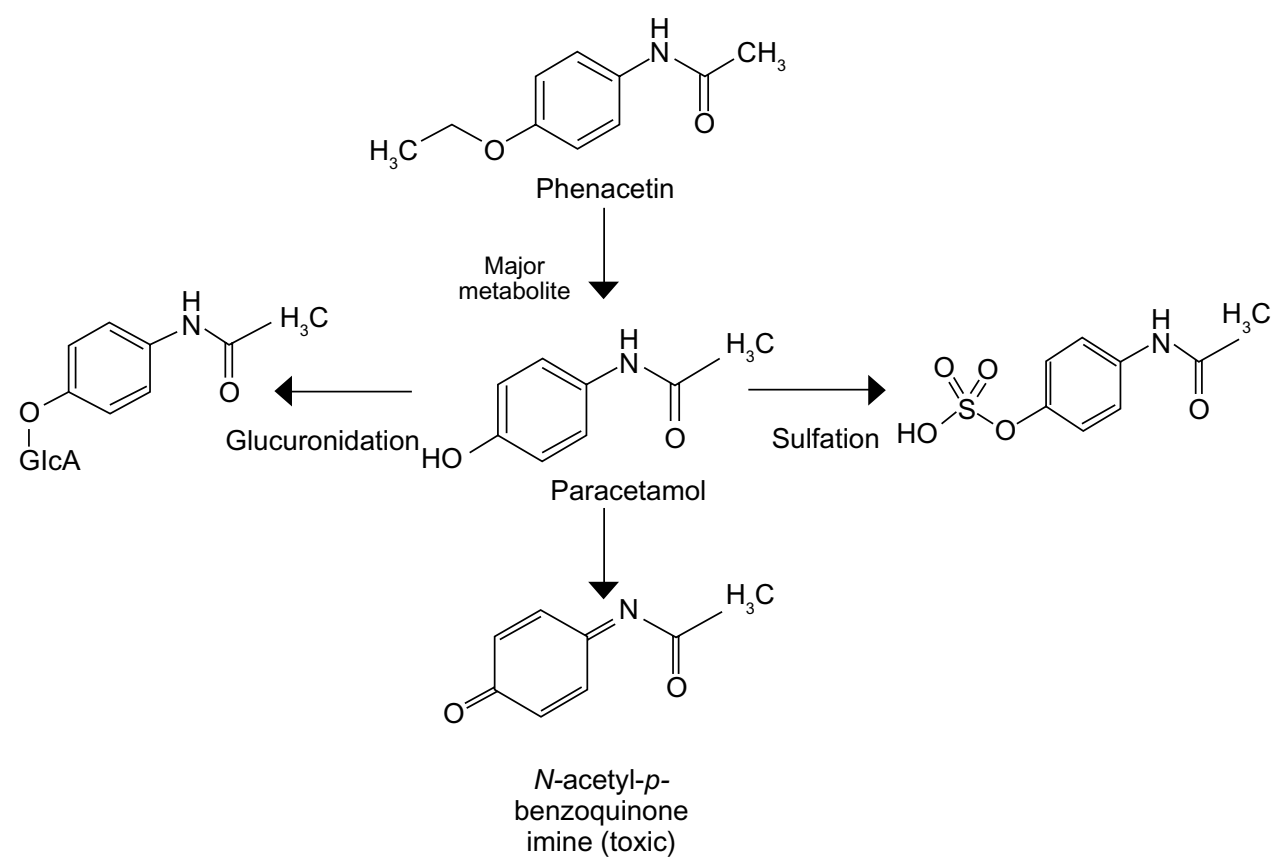

Figure I Metabolism of phenacetin to paracetamol and further metabolites.

experiments phenacetin appeared to be less nephrotoxic than the other analgesics. ${ }^{17}$ Further, the withdrawal of phenacetin in Australia in 1977 did not result in a decline of AN, as illustrated in Figure 2. ${ }^{12,18}$ On the contrary, a surge in the incidence of AN was noted for some years before a reduction. These differences presumably resulted from the misdiagnosis of NSAID-induced nephropathy. ${ }^{18}$

Several case-control studies have reported associations between chronic renal failure and other analgesic preparations, including aspirin, antipyretics, and NSAIDs in combination with caffeine, codeine, and/or barbiturates. ${ }^{19}$ The research regarding the effects of paracetamol on AN appear to be inconclusive.

Perneger et al investigated 716 patients with renal failure, and concluded that increased paracetamol use was associated with an enhanced risk of renal failure in a dose-dependent manner. ${ }^{20}$ Approximately 9\% of renal failure cases were attributable to increased paracetamol use. ${ }^{20}$ However, this study failed to adjust for the potential for patients using paracetamol to be concurrently using either phenacetin or NSAIDs when assessing association with renal failure. $^{20}$

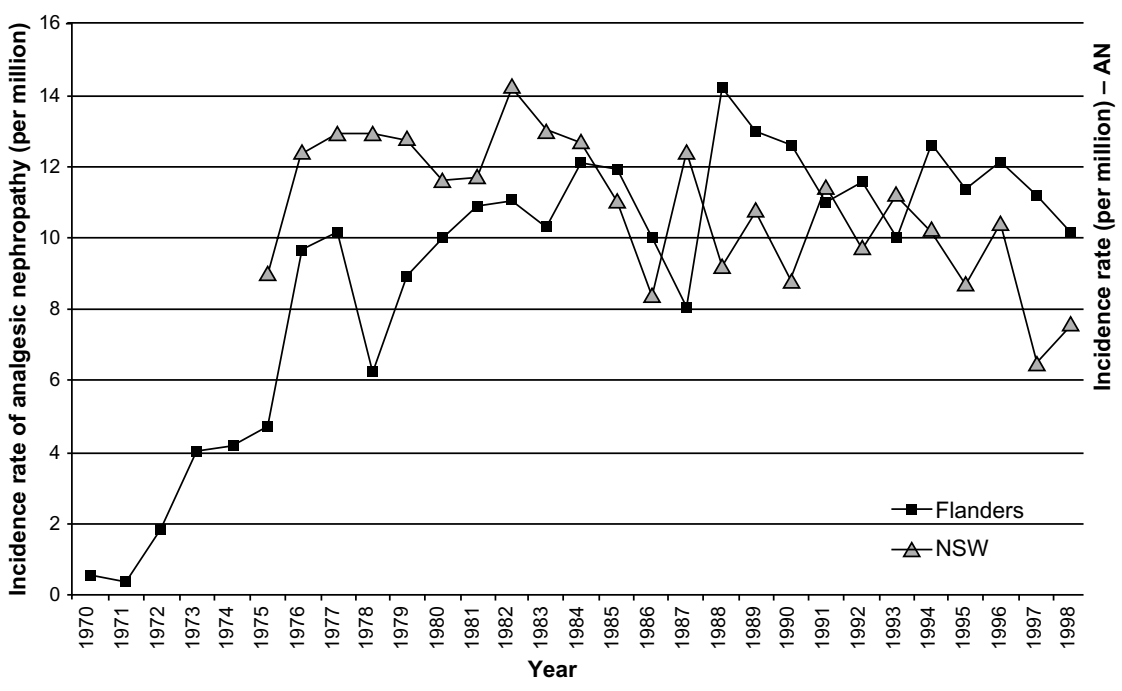

Figure 2 Incidence of analgesic nephropathy (AN) in patients admitted for renal replacement therapy in New South Wales (NSW), Australia and Flanders, Belgium. Note: Republished with permission of J Am Soc Nephrol from Trends of analgesic nephropathy in two high-endemic regions with different legislation, Michielsen P, De Schepper P, 12(3):550-556, 200 I; permission conveyed through Copyright Clearance Center, Inc. ${ }^{26}$ 
A major review by Delzell and Shapiro highlighted that most of the epidemiological evidence investigating AN has been unsatisfactory, and the research using animal models was inconsistent and not translatable to humans. ${ }^{21}$ Another review published in 2000 found no evidence between nonphenacetin combined analgesics and nephropathy. ${ }^{22}$ A 2001 study attempted to adjust for the use of other analgesics, including phenacetin, and evaluate paracetamol and aspirin use in relation to chronic renal disease. ${ }^{23}$ This study found that the regular use of paracetamol (at least twice a week for 2 months) increased the risk of developing chronic renal failure (2.5-fold increase compared to nonusers). However, consumption of these analgesics for conditions that predisposed patients to renal failure may have resulted in some bias. ${ }^{23}$

Mihatsch et al ( $\mathrm{n}=616$, autopsy examination of adult kidneys) found compelling evidence demonstrating nonphenacetin analgesics are not responsible for AN, citing a significant decline in the prevalence of AN from $\sim 4 \%$ in 1980 to $0.2 \%$ in 2000 ( 20 years after the removal of phenacetin from the analgesic market). Also, Kelkar et al conducted a retrospective case-control study of medical and pharmacy claims of a sample of 4,742 cases of renal disease, comparing chronic versus acute paracetamol use and renal disease. ${ }^{24}$ This study further confirmed that there was not a significant increase in risk for $\mathrm{AN}$ in patients exposed to accumulative dosage of at least $1 \mathrm{~kg}$ of paracetamol in the preindex year. ${ }^{24}$ Researchers, however, were unable to assess use of over-thecounter paracetamol, which would likely have strengthened results. ${ }^{24}$ Currently in Australia, paracetamol is available for purchase as an unscheduled medication as $500 \mathrm{mg}$ tablets in packets of 20 tablets or less. ${ }^{25}$ The sale of larger quantities and combination products, such as narcotic and decongestant preparations, are more highly regulated, and are required to be sold by pharmacies. ${ }^{25}$

In response to the lack of concrete data regarding causative analgesics, a peer-review committee was selected by the regulatory authorities of Germany, Switzerland, and Austria to determine the relationship between nonphenacetin analgesics and $\mathrm{AN}{ }^{22}$ The committee concluded that previously published studies to date had major flaws and failed to establish the association of analgesics other than phenacetin leading to chronic renal disease. ${ }^{22}$ In our view, patients should not be withheld an effective and commonly recommended analgesic agent for fear of worsening renal function.

\section{Conclusion}

We have presented a case of a patient who was concerned about an adverse side effect of paracetamol that has not been clearly established in the literature. The patient was reassured that paracetamol was safe. At follow-up, our patient reported recommencing paracetamol ( $665 \mathrm{mg}$ three times a day), with improvement in back pain control without deterioration of renal function.

\section{Disclosure}

The authors report no conflicts of interest in this work.

\section{References}

1. Castelino RL, Bajorek BV, Chen TF. Are interventions recommended by pharmacists during Home Medicines Review evidence-based? J Eval Clin Pract. 2011;17(1):104-110.

2. Carter SR, Chen TF, White L. Home medicines reviews: a quantitative study of the views of recipients and eligible non-recipients. Int J Pharm Pract. 2012;20(4):209-217.

3. Abdulla A, Adams N, Bone M, et al. Guidance on the management of pain in older people. Age Ageing. 2013;42:i1-i57.

4. American Geriatrics Society Panel on Pharmacological Management of Persistent Pain in Older Persons. Pharmacological management of persistent pain in older persons. J Am Geriatr Soc. 2009;57(8):1331-1346.

5. Crofford L. Rational use of analgesic and antiinflammatory drugs. N Engl J Med. 2001;345(25):1844-1846.

6. Courtney P, Doherty M. Key questions concerning paracetamol and NSAIDs for osteoarthritis. Ann Rheum Dis. 2002;61(9):767-773.

7. Sandler D, Burr F, Weinberg C. Nonsteroidal anti-inflammatory drugs and the risk for chronic renal disease. Ann Intern Med. 1991;115(3): 165-172.

8. Winkelmayer W, Walkar S, Mogun H, Solomon D. Nonselective and cyclooxygenase-2-selective NSAIDs and acute kidney injury. Am J Med. 2008;121(12):1092-1098.

9. Ejaz P, Bhojani K, Joshi V. NSAIDS and kidney. J Assoc Physicians India. 2004;52:632-640.

10. Michielsen P, Heinemann L, Mihatsch M, Schnülle P, GrafH, Koch KM. Non-phenacetin analgesics and analgesic nephropathy. Nephrol Dial Transplant. 2009;24(4):1253-1259.

11. Borne RF. Nonsteroidal anti-inflammatory agents. In: Lemke TL, Williams DA, editors. Foye's Principles of Medicinal Chemistry. 6th ed. Philadelphia: Lippincott Williams \& Wilkins; 2007.

12. Nanra R, Stuart-Taylor J, de Leon A, White K. Analgesic nephropathy: etiology, clinical syndrome, and clinicopathologic correlations in Australia. Kidney Int. 1978;13(1):79-92.

13. Stewart J. Analgesic abuse and renal failure in Australasia. Kidney Int. 1978;13(1):72-78.

14. [No authors listed]. List of drug products that have been withdrawn or removed from the market for reasons of safety or effectiveness. Food and Drug Administration, HHS. Final rule. Fed Regist. 1999;64(44): 10944-10947.

15. [No authors listed]. Some pharmaceutical drugs. IARC Monogr Eval Carcinog Risk Chem Hum. 1987;24:1-337.

16. Michielsen P. In memoriam 'analgesic nephropathy' (circa 1972-2006). Nephrol Dial Transplant. 2007;22(4):999-1001.

17. Bluemle LW Jr, Goldberg M. Renal accumulation of salicylate and phenacetin: possible mechanisms in the nephropathy of analgesic abuse. J Clin Invest. 1969;47(11):2507-2514.

18. Chang S, Mathew T, McDonald S. Analgesic nephropathy and renal replacement therapy in Australia: trends, comorbidities and outcomes. Clin J Am Soc Nephrol. 2008;3(3):768-776.

19. Broe M, Elseviers M. Over-the-counter analgesic use. JAm Soc Nephrol. 2009;20(10):2098-2103.

20. Perneger TV, Whelton PK, Klag MJ. Risk of kidney failure associated with the use of acetaminophen, aspirin, and nonsteroidal antiinflammatory drugs. $N$ Engl J Med. 1994;331(25):1675-1679. 
21. Delzell E, Shapiro S. A review of epidemiologic studies of nonnarcotic analgesics and chronic renal disease. Medicine (Baltimore). 1998;77(2):102-121.

22. Feinstein A, Heinemann L, Curhan G, et al. Relationship between nonphenacetin combined analgesics and nephropathy: a review. Ad Hoc Committee of the International Study Group on Analgesics and Nephropathy. Kidney Int. 2000;58(6):2259-2264.

23. Fored M, Ejerblad E, Lindblad P, et al. Acetaminophen, aspirin, and chronic renal failure. N Engl J Med. 2001;345(25):1801-1808.

24. Kelkar M, Cleves M, Foster H, Hogan W, James L, Martin B. Acute and chronic acetominophen use and renal disease: a case-control study using pharmacy and medical claims. J Manag Care Pharm. 2012;18(3):234-246.
25. Australian Government. The Standard for the Uniform Scheduling of Medicines and Poisons. No 4. 2013. Available from http://www.comlaw. gov.au/Details/F2014L01343. Accessed July 1, 2014.

26. Michielsen P, De Schepper P. Trends of analgesic nephropathy in two high-endemic regions with different legislation. J Am Soc Nephrol. 2001;12(3):550-556.

\section{Publish your work in this journal}

The International Medical Case Reports Journal is an international, peer-reviewed open-access journal publishing original case reports from all medical specialties. Previously unpublished medical posters are also accepted relating to any area of clinical or preclinical science. Submissions should not normally exceed 2,000 words or
4 published pages including figures, diagrams and references. The manuscript management system is completely online and includes a very quick and fair peer-review system, which is all easy to use. Visit http://www.dovepress.com/testimonials.php to read real quotes from published authors.

Submit your manuscript here: http://www.dovepress.com/international-medical-case-reports-journal-journal 